\title{
Predictors of Quitting Among African American Light Smokers Enrolled in a Randomized, Placebo-Controlled Trial
}

\author{
Nicole L. Nollen, PhD, ${ }^{1,2}$ Matthew S. Mayo, PhD, ${ }^{1,2,3}$ Lisa Sanderson Cox, PhD, ${ }^{1,2}$ \\ Kolawole S. Okuyemi, MD, MPH, ${ }^{2,4}$ Won S. Choi, PhD, MPH, ${ }^{1,2}$ Harsohena Kaur, MD, MPH, \\ Jasjit S. Ahluwalia, MD, MPH, MS \\ ${ }^{1}$ Department of Preventive Medicine and Public Health, University of Kansas Medical Center, Kansas City, KS, USA; ${ }^{2}$ Kansas Masonic \\ Cancer Research Institute, University of Kansas Medical Center, Kansas City, KS, USA; ${ }^{3}$ Center for Biostatistics and Advanced Informatics, \\ University of Kansas Medical Center, Kansas City, KS, USA; ${ }^{\circ}$ Department of Family Medicine, University of Kansas Medical Center, Kansas \\ City, KS, USA; ${ }^{5}$ Department of Pediatrics, University of Minnesota School of Medicine, Minneapolis, MN, USA; ${ }^{6}$ Department of Medicine \\ and Office of Clinical Research, University of Minnesota School of Medicine, Minneapolis, MN, USA.
}

\begin{abstract}
OBJECTIVE: To examine the predictors of quitting among African American (AA) light smokers $(<10$ cigarettes per day) enrolled in a smoking cessation trial.

METHODS: Baseline variables were analyzed as potential predictors from a $2 \times 2$ cessation trial in which participants were randomly assigned to 1 of 4 treatment groups: nicotine gum plus health education (HE) counseling, nicotine gum plus motivational interviewing (MI) counseling, placebo gum plus HE counseling, or placebo gum plus MI counseling. Chi-square tests, 2 sample $t$-tests, and multiple logistic regression analyses were used to identify predictors of cotinine (COT) verified abstinence at month 6 .
\end{abstract}

RESULTS: In the final regression model, $\mathrm{HE}$ rather than MI counseling (odds ratio $[\mathrm{OR}]=2.26 \%, 95 \%$ confidence interval $[\mathrm{CI}]=1.36$ to 3.74 ), older age $(\mathrm{OR}=1.03 \%, 95 \% \mathrm{CI}=1.01$ to 1.06$)$, and higher body mass index $(\mathrm{OR}=1.04 \%, 95 \% \mathrm{CI}=1.01$ to 1.07$)$ significantly increased the likelihood of quitting, while female gender $(\mathrm{OR}=0.46 \%, 95 \% \mathrm{CI}=0.28$ to 0.76$), \leq \$ 1,800 /$ month income $(\mathrm{OR}=0.60 \%, 95 \% \mathrm{CI}=0.37$ to 0.97 ), higher baseline COT ( $\mathrm{OR}=0.948 \%, 95 \% \mathrm{CI}=0.946$ to 0.950 ), and not completing all counseling sessions $(\mathrm{OR}=0.48 \%, 95 \% \mathrm{CI}=0.27$ to 0.84 ) reduced the odds of quitting.

CONCLUSIONS: Individual characteristics may decrease the likelihood of quitting; however, the provision of directive, advice-oriented counseling focused on the addictive nature of nicotine, health consequences of smoking, benefits of quitting, and development of a concrete quit plan may be an important and effective facilitator of quitting among AA light smokers.

KEY WORDS: smoking cessation; African Americans; light smokers. DOI: $10.1111 / \mathrm{j} .1525-1497.2006 .00404 . x$

J GEN INTERN MED 2006; 21:590-595.

$\mathrm{C}$ igarette smoking remains 1 of the leading causes of preventable disease in the United States. ${ }^{1}$ Although prevalence rates have decreased over the past few decades, the proportion of light smokers is growing. ${ }^{2,3}$ Light smoking is particularly evident among certain segments of the U.S. population, such as teens, young adults, women, and ethnic minority groups, including African Americans (AAs). While up to $50 \%$ of AAs smoke $\leq 10$ cigarettes per day (CPD) (compared with $18 \%$ to $20 \%$ found in the general population), ${ }^{3,4}$ they experience a disproportionate share of tobacco-related disease and mortality and, despite an interest in quitting, are less successful in their quit attempts compared with other racial/ ethnic groups. ${ }^{5-8}$

Address correspondence and requests for reprints to Dr. Nollen: Department of Preventive Medicine and Public Health, University of Kansas Medical Center, Mail Stop 1008, 3901 Rainbow Boulevard, Kansas City, KS 66160 (email: nnollen@kumc.edu.).
The lower rate of quitting among light smokers may be compounded by a number of key factors. First, light smokers have traditionally been excluded from smoking cessation clinical trials; therefore, little is known about the interventions most effective for this subset of smokers. Second, there is a misperception that light smokers are less addicted and can quit on their own. ${ }^{3}$ Results from our recently completed clinical trial provide evidence to the contrary. ${ }^{9}$ Specifically, following treatment with nicotine gum and counseling, month 6 quit rates among AA light smokers ranged from $6.8 \%$ to $18.0 \%$ (depending on treatment arm), which is no higher than quit rates found among heavier smokers engaged in similar pharmacologic and/or behavioral treatment programs. ${ }^{10-13}$

Quit rates among AA light smokers seen in general medical practices may be even lower. ${ }^{10}$ Primary care clinicians encounter an estimated 30 million smokers a year ${ }^{14}$ but, compared with clinical trials, experience less success in treating tobacco dependence. ${ }^{15}$ Treatment success may be improved by identifying individual factors associated with quitting and tailoring treatment to the factors most likely to facilitate or impede success among patient subgroups. Although the findings are inconsistent, several factors have been found to predict quitting among adult smokers. These factors include male gender, ${ }^{16-18}$ older age, ${ }^{19-21}$ marital status, ${ }^{22}$ educational level, ${ }^{23}$ smoking characteristics (i.e., nicotine dependence, duration of smoking, previous quit attempts, level of smoking, baseline cotinine [COT]), ${ }^{16,17,20,24}$ motivation and confidence/ self-efficacy to quit, ${ }^{19,24-26}$ negative affect, ${ }^{16,24,27,28}$ and alcohol use. ${ }^{29-31}$

Given the paucity of information about factors affecting cessation among AA light smokers, this study examined predictors of smoking cessation among AA light smokers enrolled in a randomized, placebo-controlled trial of nicotine gum and counseling. The identification of these factors could guide the treatment decisions of health care provider and increase the likelihood of quitting among this subset of smokers.

\section{METHOD}

\section{Study Design}

Data were obtained from a randomized placebo-controlled trial of nicotine gum and counseling (health education [HE] or motivational interviewing [MI]) for smoking cessation in AA light

Manuscript received September 12, 2005

Initial editorial decision November 15, 2005

Final acceptance December 23, 2005 
smokers. ${ }^{9}$ Using a $2 \times 2$ factorial design, $755(\sim 189$ in each arm) AA light smokers were randomly assigned to receive 8 weeks of active nicotine gum or placebo and $6 \mathrm{HE}$ or MI counseling sessions. All 4 arms also received a culturally sensitive smoking cessation guide developed specifically for AA light smokers. Participants were followed for a total of 6 months.

Health education is a standard counseling approach based on current treatment guidelines ${ }^{32}$ that focuses on providing information and advice. Described in detail elsewhere, ${ }^{9}$ $\mathrm{HE}$ in the current study focused on the addictive nature of nicotine, health consequences of smoking, benefits of quitting, and provided concrete strategies on developing a quit plan and identifying alternatives against triggers to smoke. Motivational interviewing is a counseling approach initially developed for addictive behaviors and more recently applied to nicotine dependence. ${ }^{33,34}$ Also described in detail elsewhere, ${ }^{9} \mathrm{MI}$ in the current study explored the pros and cons of smoking/quitting and motivation and confidence to quit. A values clarification strategy and behavioral action plan were also used.

Recruitment methods, study methodology, and smoking abstinence outcomes are described in detail elsewhere. ${ }^{9}$ Study sessions were conducted within an urban community medical clinic serving a predominantly AA clientele. Trial procedures were approved and monitored by the University of Kansas Medical Center's Human Subjects Committee.

\section{Participants}

One thousand nine hundred and thiry-three smokers completed a screening survey, 1,012 were eligible and invited to participate, and 755 were enrolled (see Fig. 1). Detailed inclusion/exclusion criteria are described in detail elsewhere ${ }^{9}$; however, to be eligible participants had to be $\geq 18$ years of age, self-identify as AA, and smoke $\leq 10$ CPD for $\geq 6$ months.

\section{Predictor Variables}

Participants completed a baseline assessment of demographic, smoking, and psychosocial characteristics. Items were derived from standardized instruments that have been described in detail elsewhere but are outlined briefly below. To reduce the number of variables included in the multivariable analyses, only those previously identified in the literature as being predictive of cessation or those thought to be clinically relevant were selected as predictor variables.

Demographics. Baseline assessment of demographic information included age, gender, marital status, income, and education. Metric measurement of height and weight were collected to calculate body mass index (BMI).

Smoking Characteristics. Serum COT, a metabolite of nicotine found in blood, saliva, or urine that is currently regarded as the best objective indicator of nicotine exposure, ${ }^{35}$ was assessed as a biomarker of baseline tobacco use. Standard smoking history questions were taken from the California Tobacco Survey ${ }^{36}$ and included CPD, type and brand of cigarettes used (menthol or nonmenthol), depth of inhalation, number of years smoked, number of quit attempts in the past year, and use of pharmacotherapy in the most recent quit attempt. Nicotine dependence was assessed using the summary score from the Nicotine Dependence Syndrome Scale ${ }^{37}$ and a single item from the Fagerstrom Test for Nicotine Dependence assessing how soon after waking the first cigarette of the day is smoked. ${ }^{38}$ Responses were collapsed into 2 categories: smoking within 30 minutes of waking or smoking after 30 minutes of waking. Motivation and confidence for quitting were assessed using a 10-point Likert scale with a higher score indicating greater motivation or confidence. ${ }^{34,39}$

Psychosocial Characteristics. Social support items included an assessment of the presence of other smokers in the home $^{40,41}$ and the existence of home smoking restrictions. ${ }^{42}$ Alcohol use was assessed using a single item from the Alcohol Use Disorders in Identification Test, ${ }^{43,44}$ "During the past 30 days, on how many days did you have at least one drink of any alcoholic beverage." The 10-item Center for Epidemiological Studies Depression Scale ${ }^{45}$ was used to measure psychological distress. Scores of 4 or higher indicate clinical levels of depression. The 4 -item perceived stress scale ${ }^{46}$ measured global life stress on a 0 - to 4-point scale. Scores of 12 or higher indicate significant perceived stress. Self-efficacy to refrain from smoking in response to internal (i.e., "When I feel nervous") and external (i.e., "When having a drink with friends") stimuli was assessed using the 12-item Smoking Self-Efficacy Questionnaire. ${ }^{47}$ Higher scores on both subscales indicate greater self-efficacy to refrain from smoking. Autonomous and controlled regulation were assessed using the 15-item Treatment Self-Regulation Questionnaire. ${ }^{48}$ This scale measures the extent to which individuals engage in a specific health behavior (i.e., quitting smoking) because it holds personal importance for them (i.e., autonomous regulation) versus doing so as a response to external pressures (i.e., controlled regulation). Higher scores indicate greater autonomous or controlled regulation.

Process Variables. Perceived autonomous support was derived from the average score on the 15-item Health Care Climate Questionnaire across the randomization, weeks 1, 8, and 26 visits. ${ }^{48,49}$ A composite score was used because it provides a more accurate reflection of the quality of the patient-provider relationship and its impact on quitting than a single point-intime score. Sample items include, "I feel that my counselor has provided me choices and options," "I don't feel very good about the way my counselor talks to me." Higher scores indicate greater perceived autonomous support. In addition, counseling session attendance was collapsed into a dichotomous variable representing those who attended all 6 sessions versus those who attended 5 or fewer sessions.

\section{Outcome Variable}

The primary outcome variable was COT-verified abstinence at month 6. Following from the recommendations of the Society for Research on Nicotine and Tobacco Subcommittee on Abstinence Measures, ${ }^{30}$ abstinence was defined as no smoking (not even a puff) in the past 7 days confirmed by a salivary COT of $\leq 20 \mathrm{ng} / \mathrm{mL}^{35}$

\section{Statistical Analysis}

Data were analyzed by imputing missing values for those lost to follow-up at month 6 and by confining analyses to participants who completed follow-up at month 6. Both analyses yielded similar findings. No variables were significantly related to the missing data. Additionally, the imputation of missing 


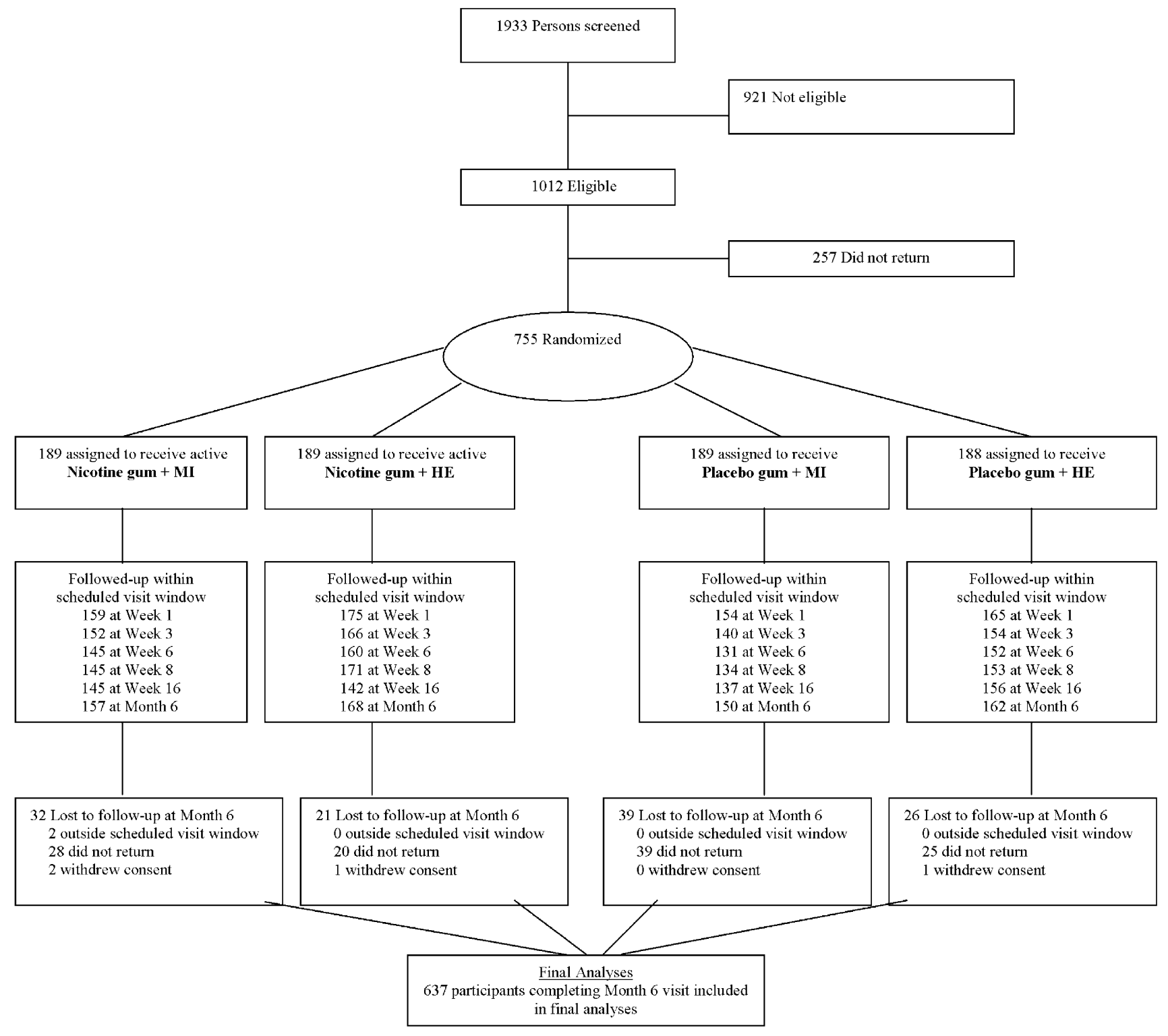

FIGURE 1. Flow of participants.

values misrepresents how counseling session attendance impacts cessation, therefore only the completers findings are presented. Categorical variables were summarized by frequencies and percentages. Continuous-level variables were summarized by means and standard deviations. Across the 2 groups by follow-up smoking status, categorical variables were compared between smoking status using the $\chi^{2}$ test and continuous variables were compared using the 2 sample $t$-tests. Logistic regression was employed to assess the 29 factors as potential predictors of abstinence from smoking in participants from all 4 study arms. Multiple logistic regression analysis, controlling for counseling and pharmacotherapy, with full stepwise and best subset variable selection procedures were performed to identify a set of multiple predictors of COT verified 7-day point prevalence abstinence from smoking at 6 months. Main effect terms for predictors were included in the first step of model selection process. All 2-way interactions were then assessed for the final set of predictors that were identified. The subset of predictors in the final selected model was all statistically significant $(P<.05)$.

\section{RESULTS}

Of the 637 participants who completed their month $6 \%$ visit, $68.1 \%$ were female, and $84.3 \%$ had at least a high school education. Their mean age was $45.6(\mathrm{SD}=10.5)$ years. Participants smoked, on average, $7.4(\mathrm{SD}=3.2) \mathrm{CPD}$, had made 3.2 $(\mathrm{SD}=6.7) 24$ hour quit attempts in the past year, and had been smoking for a mean of $24.5(\mathrm{SD}=11.9)$ years. Of the 637 participants who completed their month 6 visit (118 were lost to follow-up), 95 (14.9\%) were verified quit while 542 (85.1\%) continued to smoke. As previously reported, ${ }^{9}$ the trial found a treatment effect for counseling but not gum. Specifically, participants randomized to $\mathrm{HE}$ were more than twice as likely to quit smoking at month 6 compared with those who received MI (odds ratio $[\mathrm{OR}]=2.17 \%, 95 \%$ confidence interval $[\mathrm{CI}]=1.38$ to 
Table 1. Analysis of Categorical Baseline Predictors of Cotinine Verified Quitting at Month 6

\begin{tabular}{|c|c|c|c|}
\hline Baseline Predictors & $n$ & $\%$ Abstinent & $P^{*}$ \\
\hline \multicolumn{4}{|l|}{ Gender } \\
\hline Male & 203 & 21.7 & .001 \\
\hline Female & 434 & 11.8 & \\
\hline \multicolumn{4}{|l|}{ Married or living with partner } \\
\hline No & 398 & 13.3 & .13 \\
\hline Yes & 238 & 17.7 & \\
\hline \multicolumn{4}{|l|}{ High school graduate } \\
\hline No & 100 & 14.0 & .78 \\
\hline Yes & 537 & 15.1 & \\
\hline \multicolumn{4}{|l|}{ Income $>\$ 1,800 / \mathrm{mo}$} \\
\hline No & 359 & 11.4 & .005 \\
\hline Yes & 262 & 19.5 & \\
\hline \multicolumn{4}{|l|}{ Smokes menthol cigarettes } \\
\hline No & 122 & 21.3 & .02 \\
\hline Yes & 514 & 13.4 & \\
\hline \multicolumn{4}{|l|}{ Smokes first cigarette within 30 min of waking ${ }^{\dagger}$} \\
\hline No & 215 & 20.9 & .002 \\
\hline Yes & 420 & 11.9 & \\
\hline \multicolumn{4}{|l|}{ Depth of inhalation } \\
\hline Into the chest & 348 & 15.8 & .51 \\
\hline Into the throat, mouth, or don't really inhale & 287 & 13.9 & \\
\hline \multicolumn{4}{|l|}{ Other smokers in the household } \\
\hline No & 397 & 16.4 & .18 \\
\hline Yes & 240 & 12.5 & \\
\hline \multicolumn{4}{|l|}{ Home smoking rules } \\
\hline No rules & 300 & 15.0 & .95 \\
\hline Smoking restricted & 337 & 14.8 & \\
\hline \multicolumn{4}{|l|}{ Use of pharmacotherapy on last quit attempt } \\
\hline No & 486 & 16.1 & .68 \\
\hline Yes & 117 & 14.5 & \\
\hline \multicolumn{4}{|l|}{ Attended all counseling sessions } \\
\hline No & 220 & 8.6 & .001 \\
\hline Yes & 417 & 18.2 & \\
\hline
\end{tabular}

$* \chi^{2}$-test.

'Single item from the Fagerstrom test for nicotine dependence.

3.41); however participants who received nicotine gum were no more likely to quit smoking than those who received placebo $(\mathrm{OR}=1.31 \%, 95 \% \mathrm{CI}=0.84$ to 2.02$)$. Given the known effect of treatment on month 6 quitting, counseling and gum were included in the final regression model of the present study. This approach allowed us to examine individual predictors of cessation over and above the effects of treatment.

Differences across categorical and continuous baseline predictors among smokers and quitters verified by COT at month 6 are presented in Tables 1 and 2 . Univariate predictors of cessation were male gender $(P<.001)$, older age $(P<.05)$, smoking nonmenthol cigarettes $(P<.05)$, higher BMI $(P<.01)$, higher income $(P<.01)$, smoking fewer $\mathrm{CPD}(P<.05)$, lower baseline COT $(P<.0001)$, smoking the first cigarette of the day after 30 minutes of waking $(P<.01)$, greater confidence in the ability to quit $(P<.05)$, feeling supported by their counselor $(P<.01)$ and completing more counseling sessions $(P<.001)$.

Results of the multiple logistic regression analysis are presented in Table 3. Participants who received HE counseling were more than twice as likely to quit smoking at month 6 as those who received $\mathrm{MI}(\mathrm{OR}=2.26 \%, 95 \% \mathrm{CI}=1.36$ to 3.74$)$. Over and above the effect of treatment, 6 predictor variables were retained in the full model. Specifically, being older $(\mathrm{OR}=1.03 \%, 95 \% \mathrm{CI}=1.01$ to 1.06$)$ and having a higher $\mathrm{BMI}$ $(\mathrm{OR}=1.04 \%, 95 \% \mathrm{CI}=1.01$ to 1.07$)$ significantly increased the likelihood of quitting at month 6 , while being female $(\mathrm{OR}=0.46 \%, 95 \% \mathrm{CI}=0.28$ to 0.76$)$, an income of $\leq \$ 1,800$
Table 2. Analysis of Continuous Baseline Predictors of Cotinine Verified Quitting at Month 6

\begin{tabular}{|c|c|c|c|}
\hline Baseline Predictors & $\begin{array}{l}\text { Abstinent, mean } \\
\text { (SD) }\end{array}$ & $\begin{array}{l}\text { Smoker, mean } \\
\text { (SD) }\end{array}$ & $P^{*}$ \\
\hline Age & $47.6(10.9)$ & $45.3(10.5)$ & .05 \\
\hline Cigarettes per day & $6.8(3.3)$ & $7.5(3.0)$ & .04 \\
\hline Cotinine & $155.6(123.9)$ & 256.9 (154.3) & $<.0001$ \\
\hline Years smoked & $26.2(12.3)$ & $24.2(11.8)$ & .14 \\
\hline Motivation to quit & $9.0(1.5)$ & $9.0(1.6)$ & .84 \\
\hline Confidence to quit & $7.5(2.3)$ & $7.0(2.6)$ & .03 \\
\hline $\begin{array}{l}\text { Number of } 24 \mathrm{~h} \text { quit } \\
\text { attempts in } \\
\text { past year }\end{array}$ & $3.3(6.4)$ & $3.2(6.8)$ & .87 \\
\hline $\begin{array}{l}\text { Days used alcohol in past } \\
\text { month }\end{array}$ & $3.9(6.7)$ & $4.9(7.7)$ & .16 \\
\hline Body mass index & $33.1(8.8)$ & $30.3(7.9)$ & .005 \\
\hline Nicotine dependence ${ }^{\dagger}$ & $-0.9(1.0)$ & $-0.9(1.0)$ & .88 \\
\hline $\begin{array}{l}\text { Self-efficacy to refrain from } \\
\text { internal stimuli }\end{array}$ & $15.6(5.2)$ & $15.3(5.4)$ & .59 \\
\hline $\begin{array}{l}\text { Self-efficacy to refrain from } \\
\text { external stimuli }\end{array}$ & $14.4(6.1)$ & $13.9(6.2)$ & .46 \\
\hline Autonomous regulation & $40.0(2.7)$ & $39.7(3.6)$ & .39 \\
\hline Controlled regulation & $23.5(10.5)$ & $20.7(10.0)$ & .58 \\
\hline Depression & $3.3(2.4)$ & $3.5(2.6)$ & .39 \\
\hline Perceived stress & $8.5(2.1)$ & $8.7(2.0)$ & .44 \\
\hline Autonomous support ${ }^{\ddagger}$ & $100.8(4.1)$ & $99.0(7.2)$ & .001 \\
\hline
\end{tabular}

*t-test.

'Derived from the summary score from the Nicotine Dependence Syndrome Scale.

${ }^{\ddagger}$ Derived from the average Health Care Climate Questionnaire score at the randomization, weeks 1,8 , and 26 visits.

per month $(\mathrm{OR}=0.60 \%, 95 \% \mathrm{CI}=0.37$ to 0.97$)$, higher baseline $\mathrm{COT}(\mathrm{OR}=0.948 \%, 95 \% \mathrm{CI}=0.946$ to 0.950$)$, and not completing all counseling sessions $(\mathrm{OR}=0.48 \%$, 95\% $\mathrm{CI}=0.27$ to 0.84 ) significantly reduced the odds of quitting. None of the 2-way interactions for the final subset of predictors were statistically significant, and therefore, were not included in the final model.

\section{DISCUSSION}

This is the first known study to identify factors associated with smoking cessation among AA light smokers. At 6 months postbaseline, receiving directive, advice oriented counseling was the biggest predictor of quitting, with participants receiving $\mathrm{HE}$ counseling being more than twice as likely to quit as those who

Table 3. Final Regression Model of Baseline Variables Predicting Cotinine Verified Quitting at Month 6

\begin{tabular}{lcc}
\hline \hline Baseline Variables & $\begin{array}{c}\text { Odds ratio (95\% Confidence } \\
\text { Interval) }\end{array}$ & $\boldsymbol{P}$ \\
\hline Drug (gum =1) & $1.43(0.88$ to 2.32$)$ & .15 \\
Counseling (health & $2.26(1.36$ to 3.74$)$ & .006 \\
education $=1)$ & $0.46(0.28$ to 0.76$)$ & .002 \\
Gender (female $=1)$ & $0.60(0.37$ to 0.97$)$ & .03 \\
Income $(\leq \$ 1,800=1)$ & $1.03(1.01$ to 1.06$)$ & .007 \\
Age & $1.04(1.01$ to 1.07$)$ & .01 \\
Body mass index & $0.948(0.946$ to 0.950$)$ & $<.0001$ \\
Cotinine level* & $0.48(0.27$ to 0.84$)$ & .01 \\
Counseling sessions (didn't & & \\
\hline complete all sessions =1) & & \\
\hline
\end{tabular}

*The odds ratio shown is for a 10 unit change (e.g., increase of cotinine level from 20 to 30). 
received MI. Over and above the effect of treatment, the probability of cessation increased by $3 \%$ for each year of age and by $4 \%$ for each unit increase in BMI. However, the probability of cessation decreased by $54 \%$ for women, by $40 \%$ for individuals with a monthly income of $\leq \$ 1,800$, by $5 \%$ for every 10 unit increase in COT, and by $52 \%$ for participants who completed 5 or fewer counseling sessions. These findings are consistent with previous studies conducted among predominantly Caucasian smokers, which have found that male gender, older age, smoking characteristics (i.e., COT), and treatment compliance are associated with the likelihood of quitting. ${ }^{16-20}$ Only 1 known study has explored predictors of cessation among AA smokers. ${ }^{24}$ Although different from the current study in that it focused on AA heavy smokers ( $>10 \mathrm{CPD}$ ) similar factors, including treatment and baseline COT, were found to be related to cessation.

Interestingly, we also found that quitting was associated with monthly income and BMI. These factors have not consistently been identified in the literature, and therefore, may be unique contributors to cessation among AA light smokers. Although speculative, monthly income in the present study may have served as a proxy for stress and the challenges/barriers associated with living in poverty. These factors may adversely impact the likelihood of quitting. With regard to BMI, it is possible that participants with a higher BMI did not smoke to control their weight and/or may not have been as concerned about gaining weight during the quitting process, therefore explaining the positive relationship found between BMI and quitting. Alternatively, it is possible that participant with a higher BMI had other health problems or were concerned with improving their health status and thus more determined to quit. Future research is needed to further explore these speculations.

Knowledge of individual factors associated with quitting may guide providers' treatment-related decisions and help in tailoring treatment to the factors most likely to facilitate or impede success among patient subgroups. Drawing from the present study it appears that directive, advice-oriented counseling delivered at regular intervals (i.e., approximately 6 times over the course of 6 months) is a strong facilitator to quitting, while AA light smokers who are women, younger in age, those with a lower monthly income and BMI, higher baseline COT, and those who do not attend all counseling visits may experience increased difficulty quitting. Further, univariate results suggest that smoking menthol cigarettes, greater nicotine dependence, smoking more CPD, lower confidence to quit, and feeling less supported by a counselor/provider may be additional risk factors. Patients meeting criteria suggestive of a decreased likelihood of success may benefit from targeted, prolonged counseling, pharmacotherapy, and frequent follow-up visits. Targeted counseling might include the provision of information and advice and focus on issues such as nicotine dependence (including higher tar/nicotine menthol cigarettes, CPD, baseline COT), the link between poverty, stress, and smoking, weight concerns associated with quitting, strategies to increase confidence, and increasing compliance with behavioral treatment.

Surprisingly, nicotine dependence, confidence/self-efficacy to quit, social support, previous quit attempts, duration of smoking, negative affect, and alcohol use were not significant predictors of cessation in the final multivariate model, although previous research has found them to be consistently associated with quitting among predominantly Caucasian smokers. ${ }^{16,17,19,20,22,24-31}$ It is possible that these are not facilitative factors to cessation among AA light smokers; however, this interpretation should be made cautiously. Our measure of social support comprised only home smoking restrictions and the presence of other smokers in the home, while a single item from the FTND served as a proxy for nicotine dependence. We found limited variability in confidence to quit smoking, indicating that a more sensitive measure of confidence may be needed in this population. Additionally, it may be that problem drinking rather than alcohol use in the past month is a better predictor of smoking cessation. Given these factors, more research is needed to further elucidate the impact of race/ethnicity and the role of these factors in predicting cessation among AA light smokers.

The current study has limitations. Our sample consisted of self-selected smokers who were motivated to quit, therefore caution should be taken in generalizing our findings to smokers who are not interested in quitting. The study was conducted at a single health care facility; however community-wide recruitment resulted in a more demographically diverse and representative sample of AA light smokers. Finally, although all participants smoked at their current rate for $\geq 6$ months we did not assess whether some were former heavy smokers on their way to quitting. Factors affecting cessation among this transitional group of smokers may be different; therefore, caution should be taken in generalizing our findings to former heavier smokers engaged in the gradual reduction process.

In sum, while individual risk factors may influence cessation, the provision of brief information and advice focused on the addictive nature of nicotine, health consequences of smoking, benefits of quitting, identifying alternatives against triggers to smoke, and developing a concrete quit plan appears to be an important and effective facilitator of quitting among AA light smokers.

This project was supported by the National Cancer Institute at the National Institutes of Health (NIH RO1 CA91912). A grant from the National Institutes of Health is pending for Dr Sanderson Cox (NIH RO1).

\section{REFERENCES}

1. Mokdad AH, Marks JS, Stroup DF, Gerberding JL. Actual causes of death in the United States, 2000. JAMA. 2004;291:1238-45.

2. Kandel DB, Chen K. Extent of smoking and nicotine dependence in the United States: 1991-1993. Nicotine Tob Res. 2000;2:263-74.

3. Okuyemi KS, Harris KJ, Scheibmeir M, Choi WS, Powell J, Ahluwalia JS. Light smokers: issues and recommendations. Nicotine Tob Res. 2002;4(suppl 2):S103-S112.

4. Centers for Disease Control and Prevention. Cigarette smoking among adults-United States, 2003. MMWR. 2005;54:509-13.

5. Caraballo RS, Giovino GA, Pechacek TF, et al. Racial and ethnic differences in serum cotinine levels of cigarette smokers: third national health and nutrition examination survey, 1988-1991. JAMA. 1998;280: 135-9.

6. Harris RE, Zang EA, Anderson JI, Wynder EL. Race and sex differences in lung cancer risk associated with cigarette smoking. Int $\mathrm{J}$ Epidemiol. 1993;22:592-9.

7. Okuyemi KS, Ahluwalia JS, Banks R, et al. Differences in smoking and quitting experiences by levels of smoking among African Americans. Ethn Dis. 2004; 14:127-33.

8. Perez-Stable EJ, Herrera B, Jacob P III, Benowitz NL. Nicotine metabolism and intake in black and white smokers. JAMA. 1998;280: 152-6. 
9. Ahluwalia JS, Okuyemi KS, Nollen NL, et al. The effects of nicotine gum and counseling among African American light smokers: A $2 \times 2$ factorial design. Addiction, (in press).

10. Fiore M BW, Cohen S. Treating Tobacco Use and Dependence: Clinical Practice Guideline. Washington, DC: U.S. Department of Health and Human Services. Public Health Service; 2000.

11. Huibers MJ, Beurskens AJ, Bleijenberg G, van Schayck CP. The effectiveness of psychosocial interventions delivered by general practitioners. Cochrane Database Syst Rev. 2003; (2): CD003494.

12. Lancaster T, Stead LF.. Individual behavioural counselling for smoking cessation. Cochrane Database Syst Rev. 2005; (2) CD001292.

13. Silagy C, Lancaster T, Stead L, Mant D, Fowler G. Nicotine replacement therapy for smoking cessation. Cochrane Database Syst Rev. 2004; (4) CD 000146.

14. Centers for Disease Control and Prevention (CDC). Physician and other health-care professional counseling of smokers to quit-United States, 1991. MMWR. 1993;42:854-7.

15. Lancaster T, Stead LF. Physician advice for smoking cessation. Cochrane Database Syst Rev. 2004; (4) CD000165.

16. Ferguson JA, Patten CA, Schroeder DR, Offord KP, Eberman KM, Hurt RD. Predictors of 6-month tobacco abstinence among 1224 cigarette smokers treated for nicotine dependence. Addict Behav. 2003;28:1203-18

17. Dale LC, Glover ED, Sachs DP, et al. Bupropion for smoking cessation: predictors of successful outcome. Chest. 2001;119:1357-64.

18. Wetter DW, Kenford SL, Smith SS, Fiore MC, Jorenby DE, Baker TB. Gender differences in smoking cessation. J Consult Clin Psychol. 1999;67:555-62.

19. MacKenzie TD, Pereira RI, Mehler PS. Smoking abstinence after hospitalization: predictors of success. Prev Med. 2004;39:1087-92.

20. Grandes G, Cortada JM, Arrazola A, Laka JP. Predictors of long-term outcome of a smoking cessation programme in primary care. $\mathrm{Br} \mathrm{J}$ Gen Pract. 2003;53:101-7.

21. Sherman SE, Wang MM, Nguyen B. Predictors of success in a smoking cessation clinic. J Gen Intern Med. 1996;11:702-4.

22. O'Loughlin J, Paradis G, Renaud L, Meshefedjian G, Barnett T. The "Yes, I Quit" smoking cessation course: does it help women in a low income community quit? J Community Health. 1997;22:451-68.

23. Nides MA, Rakos RF, Gonzales D, et al. Predictors of initial smoking cessation and relapse through the first 2 years of the lung health study. J Consult Clin Psychol. 1995;63:60-9.

24. Harris KJ, Okuyemi KS, Catley D, Mayo MS, Ge B, Ahluwalia JS. Predictors of smoking cessation among African-Americans enrolled in a randomized controlled trial of bupropion. Prev Med. 2004;38: 498-502.

25. Borrelli B, Mermelstein R. The role of weight concern and self-efficacy in smoking cessation and weight gain among smokers in a clinic-based cessation program. Addict Behav. 1998;23:609-22.

26. Dale LC, Olsen DA, Patten CA, et al. Predictors of smoking cessation among elderly smokers treated for nicotine dependence. Tob Control. 1997;6:181-7

27. Glassman AH, Helzer JE, Covey LS, et al. Smoking, smoking cessation, and major depression. JAMA. 1990;264:1546-9.

28. Killen JD, Fortmann SP, Kraemer HC, Varady AN, Davis L, Newman B. Interactive effects of depression symptoms, nicotine dependence, and weight change on late smoking relapse. J Consult Clin Psychol. 1996;64:1060-7.

29. Bobo JK, Lando HA, Walker RD, McIlvain HE. Predictors of tobacco quit attempts among recovering alcoholics. J Subst Abuse. 1996;8:431-43.
30. Hughes JR. Treatment of smoking cessation in smokers with past alcohol/drug problems. J Subst Abuse Treat. 1993;10:181-7.

31. Morgenstern J, Labouvie E, McCrady BS, Kahler CW, Frey RM. Affiliation with alcoholics anonymous after treatment: a study of its therapeutic effects and mechanisms of action. J Consult Clin Psychol. 1997;65:768-77.

32. A clinical practice guideline for treating tobacco use and dependence: A US Public Health Service report. The tobacco use and dependence clinical practice guideline panel, staff, and consortium representatives. JAMA. 2000;283:3244-54.

33. Miller WR, Rollnick S. Motivational Interviewing: Preparing People for Change. 2nd edn. New York: Guilford Press; 2002.

34. Rollnick S, Butler CC, Stott N. Helping smokers make decisions: the enhancement of brief intervention for general medical practice. Patient Educ Couns. 1997;31:191-203.

35. SRNT Subcommittee on Biochemical Verification. Biochemical verification of tobacco use and cessation. Nicotine Tob Res. 2002;4:149-59.

36. California Department of Health and Human Services, Tobacco Control Section (1999). California Tobacco Survey: 1999. La Jolla, CA: Cancer Prevention and Control Unit; 2002

37. Shiffman S, Waters A, Hickcox $\mathbf{M}$. The nicotine dependence syndrome scale: a multidimensional measure of nicotine dependence. Nicotine Tob Res. 2004;6:327-48.

38. Heatherton TF, Kozlowski LT, Frecker RC, Fagerstrom KO. The Fagerstrom test for nicotine dependence: a revision of the Fagerstrom Tolerance Questionnaire. Br J Addict. 1991;86:1119-27.

39. Resnicow K, Wallace DC, Jackson A, et al. Dietary change through African American churches: baseline results and program description of the eat for life trial. J Cancer Educ. 2000;15:156-63.

40. Third National Health and Nutrition Examination Survey (NHANES III). (1988-1994) Survey data, Division of Health Examination Statistics National Center for Health Statistics (NCHS), Centers for Disease Control and Prevention.

41. Okah FA, Choi WS, Okuyemi KS, Ahluwalia JS. Effect of children on home smoking restriction by inner-city smokers. Pediatrics. 2002;109:244-9.

42. U.S. Department of Commerce, Census Bureau, National Cancer Institute. Tobacco Use Supplement to the Current Population Survey, 1998. Washington, DC: U.S. Department of Commerce, Census Bureau, National Cancer Institute; 1998.

43. Isaacson JH, Butler R, Zacharek M, Tzelepis A. Screening with the alcohol use disorders identification test (AUDIT) in an inner-city population. J Gen Intern Med. 1994;9:550-3.

44. Babor TF, Grant M. From clinical research to secondary prevention: International collaboration in the development of the alcohol use disorders identification test. Alcohol Health Res World. 1989;13:371-4.

45. Irwin M, Artin KH, Oxman MN. Screening for depression in the older adult: criterion validity of the 10-item center for epidemiological studies depression scale (CES-D). Arch Intern Med. 1999;159:1701-4.

46. Cohen S, Kamarck T, Mermelstein R. A global measure of perceived stress. J Health Soc Behav. 1983;24:385-96.

47. Etter JF, Bergman MM, Humair JP, Perneger TV. Development and validation of a scale measuring self-efficacy of current and former smokers. Addiction. 2000;95:901-13.

48. Williams GC, Gagne M, Ryan RM, Deci EL. Facilitating autonomous motivation for smoking cessation. Health Psychol. 2002;21:40-50.

49. Williams GC, Grow VM, Freedman ZR, Ryan RM, Deci EL. Motivational predictors of weight loss and weight-loss maintenance. J Pers Soc Psychol. 1996;70:115-26. 